\title{
SENSIBILITÉ DU BROCHET (ESOX LUCIUS) A DIFFÉRENTS VIRUS DE SALMONIDÉS (NPI, SHV, NHI) ET AU RHABDOVIRUS DE LA PERCHE
}

\author{
M. DORSON, P. de KINKELIN, Corinne TORCHY et Danièle MONGE
}

Laboratoire d'Ichtyopathologie, I.N.R.A., 78850 THIVERVAL-GRIGNON, France.

Reçu le 10 juin 1987

Accepté le 12 août 1987

Received 10 June, 1987

Accepted 12 August, 1987

\section{RÉSUMÉ}

Des alevins de brochet âgés de 10 jours à 2 mois ont été soumis à l'infection expérimentale par 4 souches de virus de salmonidés (NPI, NHI, SHV types 1 et 3 ) et par le rhabdovirus de la perche. Le virus de la NPI a provoqué une mortalité de $74 \%$ chez des alevins âgés de 10 jours, avec comme principaux signes cliniques une exophtalmie et un ballonnement abdominal consécutif à l'accumulation de liquide. L'histopathologie a permis de retrouver les lésions pancréatiques habituelles chez les salmonidés, accompagnées d'une hépatite nécrosante remarquable et de lésions cardiaques. Les alevins âgés de deux mois ont parfaitement résisté à l'infection par la NPI.

Les 4 rhabdovirus, y compris celui de la perche, ont provoqué des hémorragies souvent accompagnées d'exophtalmie, entrainant des mortalités comprises entre 40 et $70 \%$ sur des alevins âgés de 1 à 2 mois

Ces résultats montrent ou confirment l'extrême réceptivité de l'alevin de brochet aux principaux virus des salmonidés, en y ajoutant le rhabdovirus de la perche.

\section{SUSCEPTIBILITY OF PIKE (ESOX LUCIUS) TO DIFFERENT SALMONID VIRUSES} (IPN, VHS, IHN) AND TO THE PERCH RHABDOVIRUS

\section{SUMMARY}

Pike fry (age from 10 days to 2 months) have been experimentally infected by 4 salmonid virus strains (IPN, IHN, VHS types 1 and 3 ) and by perch rhabdovirus. IPN virus caused a $74 \%$ mortality in 10 days old fry, with exophtalmia and abdominal swelling due to liquid accumulation. Histopathologic examination showed the pancreatic lesions usual in salmonids, but also a remarkable necrosis of liver and cardiac tissues. Two months old fry proved resistant to IPN infection.

The four rhabdoviruses, including perch virus, provoked haemorrhages with frequent exophthalmia, followed by mortalities ranging from 40 to $70 \%$ in 1 to 2 months old fry. These results show or confirm the extreme susceptibility of pike fry to the principal salmonid viruses and to perch rhabdovirus.

\section{INTRODUCTION}

Si on excepte la preuve de l'étiologie virale du lymphosarcome du brochet (Esox lucius), apportée en 1970 par la transmission à l'aide d'extraits de lésions filtrés (MULCAHY et O'LEARY, 1970), sans que le virus ait jusqu'à présent pu être isolé, ce n'est qu'en 1973 que fut isolé par DE KINKELIN, GALIMARD et BOOTSMA le premier virus pathogène pour le brcchet nommé rhabdovirus du brochet. Ce virus provoquait une hydrocéphalose chez les alevins en fin de résorption et une septicémie hémorragique chez les brochetons de 5 à $10 \mathrm{~cm}$ dans des élevages hollandais, avec dans les deux cas des mortalités importantes. La sensibilité du brocheton à un virus dont on pensait le pouvoir pathogène limité à la truite arc-en-ciel (Salmo gairdneri), le virus de la Septicémie Hémorragique Virale (SHV) de type 1, fut ensuite observée et démontrée par MEIER et JORGENSEN (1980), avec là encore une septicémie hémorragique capable d'éliminer pratiquement toute une population de brochetons de 2,5 à $3,5 \mathrm{~cm}$. La recherche plus systématique de virus chez cette espèce, d'une part, et l'infection expérimentale par des virus connus, d'autre part, ont depuis fait l'objet de l'attention de plusieurs laboratoires, avec comme handicaps par rapport aux salmonidés, la plus grande difficulté d'approvisionnement et d'élevage du brochet. Dès 1978, AHNE isolait un virus de la Nécrose Pancréatique Infectieuse (NPI) des salmonidés de sérotype Sp sur alevin de brochet, mais échouait d'abord dans la reproduction de la maladie. II y parvenait peu après (AHNE, 1980) avec un virus apparenté à celui de la NPI (sérotype He) isolé à nouveau de brochetons et non pathogène pour la truite. 
Simultanement, nous avions entrepris une évaluation du pouvoir pathogène de différents virus pour le brochet, dont les premiers résultats (concernant la SHV de types 1 et 3) ont déjà été évoqués (DORSON, DE KINKELIN et MICHEL, 1983). Cet article rapporte les résultats obtenus avec les principaux virus pathogènes pour les salmonidés. en accordant une attention particulière à celui de la NPI pour lequel l'histopathologie a révélé des différences entre le brochet et la truite sur le plan de la pathogénie.

\section{MATÉRIEL ET MÉTHODES}

\subsection{Brochets utilisés}

Les alevins et brochetons utilisés provenaient de l'écloserie du Centre du Paraclet et étaient parvenus au laboratoire sous deux formes

- Brochetons de 9 semaines, longueur 6,5 à $8 \mathrm{~cm}$, poids de 1.5 à $2 \mathrm{~g}$. pour les premières expériences (infection par la SHV). Ces poissons provenaient de la pêche de petits étangs de reproduction naturelle aménagée (BRY et al., 1983)

- Alevins vésiculés âgés de 50 degrés $x$ jours d'un poids moyen de $0,013 \mathrm{~g}$ issus de fécondation artificielle.

Suivant leur taille, les brochets ont été nourris de plancton composé en majeure partie de daphnies ( $90 \%$ ) et de copépodes (moins de $10 \%$ ) puis d'alevins de truite. Ils étaient maintenus dans des aquariums de $10 \mathrm{l}$ alimentés par de l'eau de ville maintenue entre 10 et $12^{\circ} \mathrm{C}$, à un débit d'approximativement $0.1 \mathrm{l} / \mathrm{mn}$

Suivant la taille des poissons, leur nombre par aquarium variait de 24 à 75 , et un aquarium était utilisé par souche virale, excepté pour la première infection par le virus de la NPI où deux lots de 75 alevins furent infectes.

Les effluents étaient collectés dans un bac où était maintenue une concentration supérieure à 0,2 degrés chlorométriques par adjonction régulière d'eau de Javel afin d'assurer une désinfection totale.

\subsection{Souches virales utilisées, production et titrage}

- NPI, sérotype Sp (VESTERGARD-JORGENSEN et KEHLET, 1971).

- SHV, sérotype 1 (JENSEN, 1965).

- SHV, sérotype 3 (DE KINKELIN et LE BERRE, 1977).

- Nécrose Hématopoïétique Infectieuse (NHI, AMEND, YASUTAKE et MEAD, 1969)

- Rhabdovirus de la Perche (DORSON et al., 1984).

Tous ces virus, isolés à partir de représentants mcribonds de leur hôte "officiel" avaient été produits suivant la technique décrite par DE KINKELIN et SCH:ERRER (1970) pour SHV1 sur des cellules de truite RTG2 (WOLF et OUIMBY, 1962) cultivées à $14^{\circ} \mathrm{C}$ en milieu de Eagle, modification de Stoker, additionné de phosphate de tryptose (10\%), de sérum d'embryon bovin (10\%) et d'antibiotiques (pénicilline $50 \mathrm{u}$.i./ml, streptomycine, kanamycine et mycostatine $50 \mathrm{mg} / \mathrm{l}$, tamponné à pH 7,4 par le Tris $\mathrm{HCl} 0,16 \mathrm{M}$. Lorsque l'effet cytopathogène (ECP) caractéristique du virus ètait généralisé, le surnageant infectieux était récolté, clarifié par centrifugation et stocké à $-70^{\circ} \mathrm{C}$.

Le titre viral était déterminé par la technique des plages sous agarose (décrite elle aussi par DE KINKELIN et SCHERRER, 1970), dans des boîtes de Pétri en matière plastique (diamètre $35 \mathrm{~mm}$ ) fraîchement ensemencées avec $1.5 \times 10^{6}$ cellules RTG2. Après dépôt de l'inoculum $(0.1 \mathrm{ml})$ et adsorption du virus $(1 \mathrm{~h})$, les cellules étaient recouvertes d'un milieu nutritif de Stoker gélifiè par de l'agarose à la concentration de $0,4 \%$. Trois jours après, les cellules ètaient fixées au formol à $10 \%$ et colorées par le cristal violet à $1 \%$ afin de permettre le comptage des plages de lyse et d'exprimer ainsi le titre viral en unités formant plage (u.f.p.).

A l'exception du rhabdovirus de la perche, qui avait subi 60 passages successifs en culture cellulaire depuis son isolement, tous les virus en étaient à leur second ou troisième passage.

\subsection{Infection expérimentale}

L'arrivée d'eau des aquariums était interrompue, le volume d'eau ramené à 3 l et la suspension virale ajoutée de façon à obtenir une concentration comprise entre $10^{4}$ et $5 \times 10^{4}$ u.f.p./ml. L'alimentation en eau était rétablie après 3 heures de balnéation infectante. Lors de chaque infection, un lot témoin d'effectif égal était conservé, qui subissait les mêmes manipulations que le lot infecté.

\subsection{Diagnostic virologique}

Suivant leur taille, les alevins entiers ou leur portion troncale étaient broyés dans un mortier à l'aide d'un pilon en présence de sable stérile. Le broyat était homogénéisé dans $15 \mathrm{ml}$ de solution 
tamponnée de Earle supplémentée en antibiotiques (pénicilline $100 \mathrm{u} . \mathrm{i} / \mathrm{ml}$, streptomycine $100 \mathrm{mg} / \mathrm{I}$, kanamycine $100 \mathrm{mg} / \mathrm{l}$ et mycostatine $100 \mathrm{mg} / \mathrm{l}$ ). Aprés centrifugation ( $5000 \mathrm{~g}, 20 \mathrm{mn}$.), le surnageant était prélevé stérilement et inoculé à des cellules RTG2 en monocouches $10.1 \mathrm{ml}$ pour un puits contenant environ 300.000 cellules sur $200 \mathrm{~mm}^{2}$ ). Les cellules étaient observées quotidiennement pendant 15 jours afin d'enregistrer l'apparition d'un effet cytopathogène caracteristique.

\subsection{Techniques histologiques}

Après anesthésie par immersion dans une solution de 2-phénoxyéthanol à la dilution de $1: 3.000$, des alevins normaux ou malades ont été fixés dans le liquide de Bouin pendant 3 à 7 jours et, afin de pratiquer ultérieurement des coupes longitudinales, la fixation était d'abord effectuée à plat dans des boîtes de Pétri pendant 1 à 2 heures. A partir des échantillons inclus dans la paraffine, des coupes de $5 \mu \mathrm{m}$ d'épaisseur ont été faites et colorées par l'hématoxyline-éosine pour l'examen microscopique.

\section{RESUltats}

\subsection{Mortalités (tableau 1) et signes cliniques}

Chez les alevins de brochet infectés par le virus de la NPI en fin de résorption à l'âge de 10 jours, les premières mortalités sont apparues 12 jours après l'infection, les poissons moribonds présentant de façon relativement constante une rétention liquidienne traduisant des troubles de la régulation osmotique et se manifestant par de l'exophtalmie et un ballonnement important (fig. 1). Plus de $70 \%$ des alevins ont ainsi été éliminés par l'infection virale en moins de 2 mois. En revanche les alevins plus âgés (9 semaines, 1.5 à 2 grammes) se sont montrés totalement résistants, ce qui laisse supposer pour le brochet une sensibilité limitée aux très jeunes stades comme chez la truite.

Avec le rhabdovirus de la perche, les premiers cadavres ont èté enregistrés au $8^{e}$ jour après infection, et la mortalité s'est maintenue à un rythme constant jusqu'à la fin de la $3^{\mathrm{e}}$ semaine, où ne subsistait que la moitiè de l'effectif initial. Les brochetons mourants présentaient de façon constante les signes cliniques qui seront évoqués plus loin avec la SHV: hémorragies superficielles soulignant plusieurs myoseptes consécutifs, hémorragies à la base des nageoires, hémorragies internes révélées par l'autopsie, exophtalmie fréquente (fig. 2).

Dans le cas de la NHI les brochetons, bien que moins nombreux et plus âgés, ont permis d'observer une nette sensibilité à ce virus. Là encore, les premiers morts ont été notés au $8^{\mathrm{e}}$ jour, et plus de $40 \%$ des poissons éliminés en 15 jours. Exophtalmie et hémorragies (peut-être plus discrètes qu'avec la SHV) ont été observées de façon constante (fig. 3).

Avec la SHV de types 1 et 3 ont été retrouvées les lésions décrites par MEIER et JORGENSEN (1980) : exophtalmie fréquente, et surtout hémorragies remarquables (fig. 4), accompagnées de mortalités débutant au $6^{\mathrm{e}}$ jour (type 3 ) et au $7^{\mathrm{e}}$ (type 1) et cessant après deux semaines, les mortalités cumulées obtenues avec le type 3 se maintenant à un niveau constamment supérieur.

Dans tous les cas, les lots témoins ont présenté des mortalités insignifiantes. De façon surprenante, aucun cannibalisme n'a été observé, même chez les brochetons les plus âgés.

\subsection{Diagnostic virologique}

Le virus d'infection a été retrouvé de façon absolument constante dans les cadavres soumis au diagnostic virologique (de 5 à 10 poissons suivant les lots). Dans le cas du rhabdovirus de la perche, le virus ainsi réisolé a été identifié par séroneutralisation à l'aide d'un antisérum de lapin, (DORSON et al., 1984) ceci afin d'éliminer tout soupçon concernant une éventuelle infection accidentelle par les virus de SHV utilisés à proximité en expérimentation.

\subsection{Histopathologie de la NPI}

L'étude histopathologique n'a été conduite que dans le cas de la NPI, seule des maladies considérées pour laquelle les manifestations cliniques apparaissaient notablement différentes de ce qui a été décrit pour les salmonidés. L'infection clinique par le virus de la NPI apparaît principalement comme une hépato-pancréatite nécrosante (fig. 5 et 6 ). En effet on y retrouve non seulement les îlots de nécrose du pancréas exocrine plus ou moins étendus selon les stades évolutifs et qui sont classiques chez les salmonidés réceptifs, mais aussi des lésions hépatiques notables. Ces dernières peuvent aller jusqu'à une destruction presque totale du parenchyme hépatique (fig. 7). Le foie apparaît donc beaucoup plus atteint que le pancréas. A côté de l'hépato-pancréatite existe une atteinte cardiaque qui se traduit par une certaine infiltration lymphoïde des parois atriale et ventriculaire ainsi que par des îlots nécrotiques de l'épicarde atrial et ventriculaire (fig. 8 à 10). Aucune lésion n'a été décelée dans le rein et la musculature alors que leur atteinte est de règle dans les rhabdoviroses expérimentales. 


\begin{tabular}{|l|c|rc|}
\hline Virus & $\begin{array}{c}\text { Age à l'infection } \\
\text { (jours après éclosion) }\end{array}$ & Mortalité (\%) \\
\hline NPI & 10 & $111 / 150(74)$ \\
R.P. & 35 & $34 / 66 \quad(51)$ \\
NHI & 45 & $10 / 24$ & $(42)$ \\
SHV.1 & 63 & $19 / 30$ & $(63)$ \\
SHV.3 & 63 & $21 / 30$ & $(70)$ \\
NPI & 63 & $0 / 30$ & $(0)$ \\
\hline
\end{tabular}

Tableau | : Mortalités provoquées par les virus indiqués chez des alevins de brochet infectés par bain. N.P.I.: Nécrose Pancréatique Infectieuse. R.P. : Rhabdovirus de la Perche. N.H.I.: Nécrose Hématopoïètique Infectieuse. S.H.V. : Septicémie Hémorragique Virale.

Dans chaque cas avait été conservè un lot d'effectif égal non soumis à l'infection. Aucune mortalité anormale n'a èté enregistrée dans ces lots (de 0 à 2 morts en tout par lot).

Table I : Mortalities provoked by the different viruses in pike fry infected by immersion I.P.N.: Infectious Pancreatic Necrosis. P.R. : Perch Rhabdovirus. I.H.N. : Infectious Haematopietic Necrosis. V.H.S : Viral Haemorrhagic Septicaemia.

No abnormal mortality was recorded in non-infected controls (from 0 to 2 fish per group).

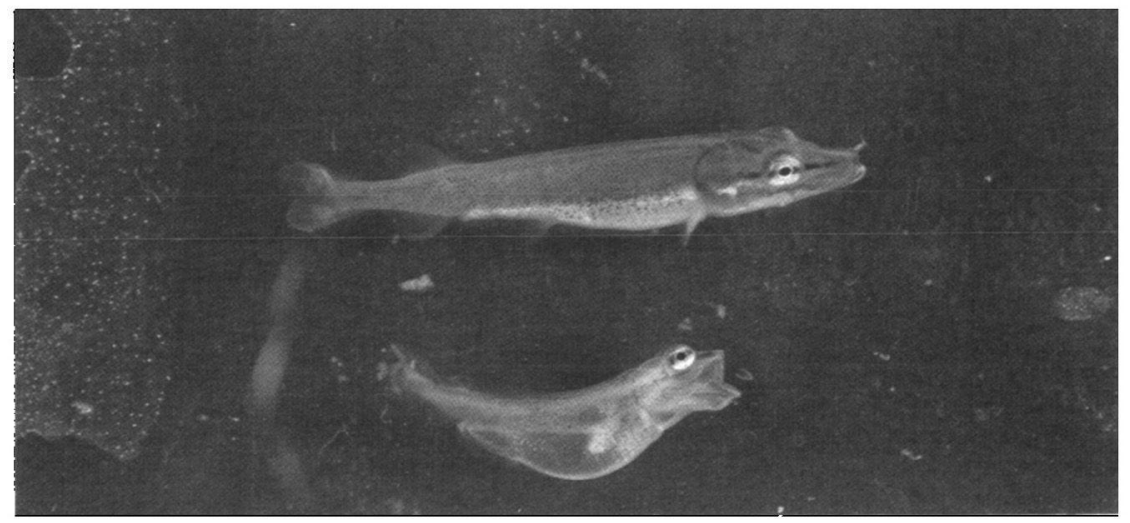

Figure 1 : Alevin de brochet normal âgé de 30 jours (en haut) et alevin du même groupe infecté par le virus de la NPI à l'âge de 10 jours (en bas), chez lequel l'accumulation de liquide dans la cavité générale est bien visible.

Figure 1 : Normal pike alevin (age : 30 days, upper), and alevin from the same group infected by IPNV when 10 days old (lower), with accumulation of liquid in the general cavity. 


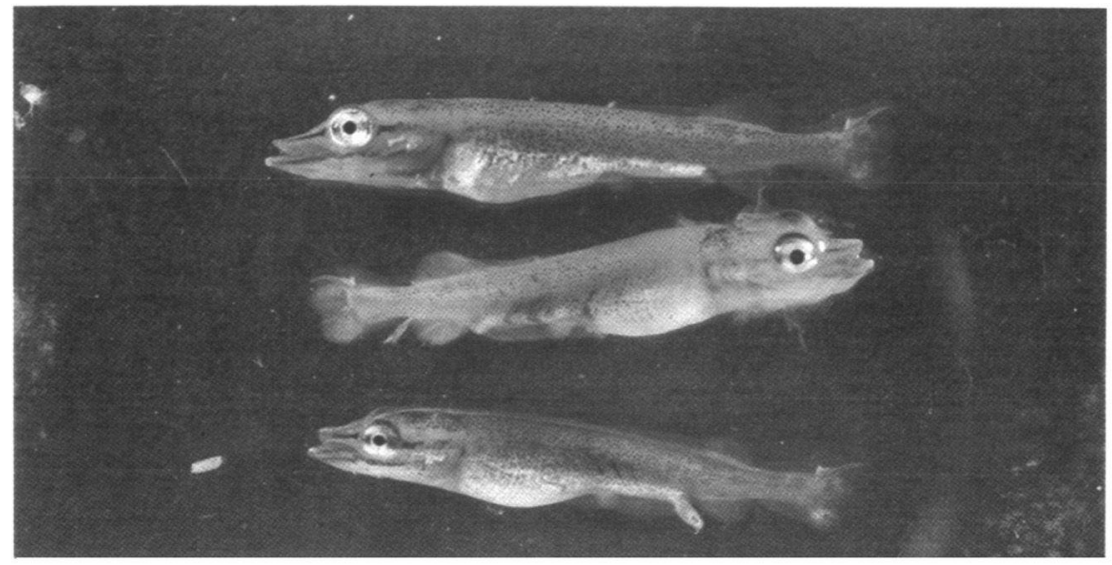

Figure 2 : Alevin de brochet normal âgé de 6 semaines (en haut) et alevins du même groupe infectés par le rhabdovirus de la perche à l'âge de 35 jours (en bas), présentant une exophtalmie et des hémorragies dans les espaces intermusculaires.

Figure 2 : Normal pike alevin (age : 6 weeks, upper) and alevins from the same group infected by perch rhabdovirus when 35 days old (lower), with exophthalmia and haemorrhages in the intermuscular spaces.

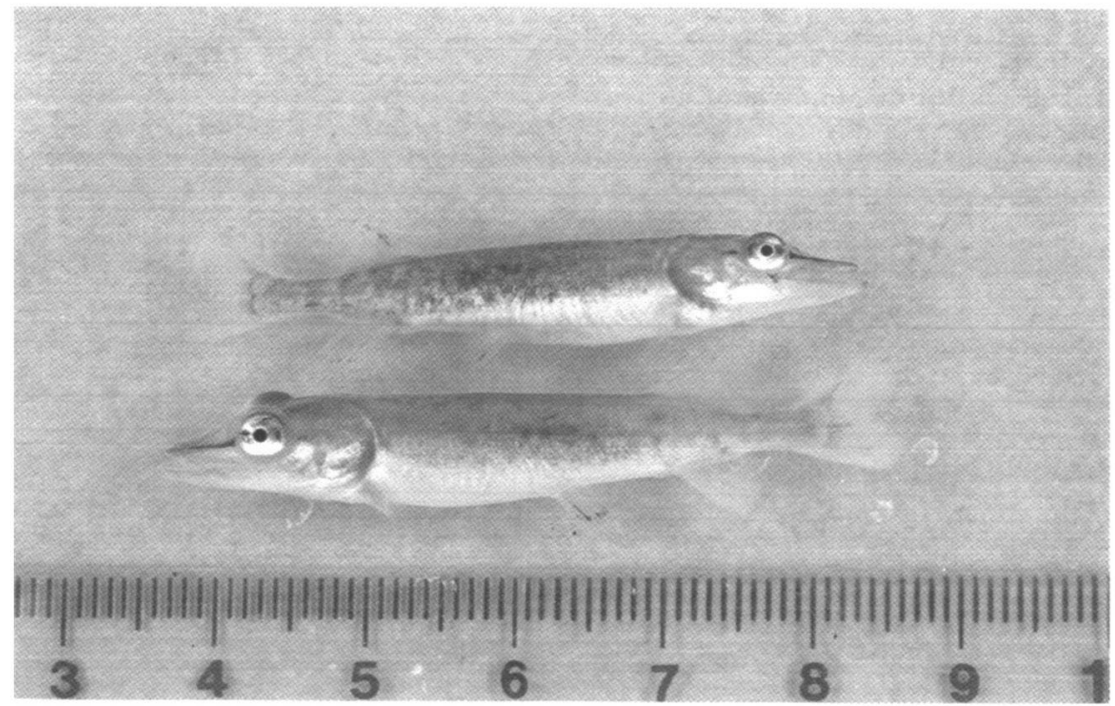

Figure 3 : Deux brochetons ãgés de 2 mois et infectés par le virus de la NHI à l'âge de 45 jours: exophtalmie, hémorragies sur les flancs et les nageoires.

Figure 3 : Two small pike (age : 2 months) infected by IHNV when 45 days old : exophtalmia and haemorrhages on the sides and fins. 


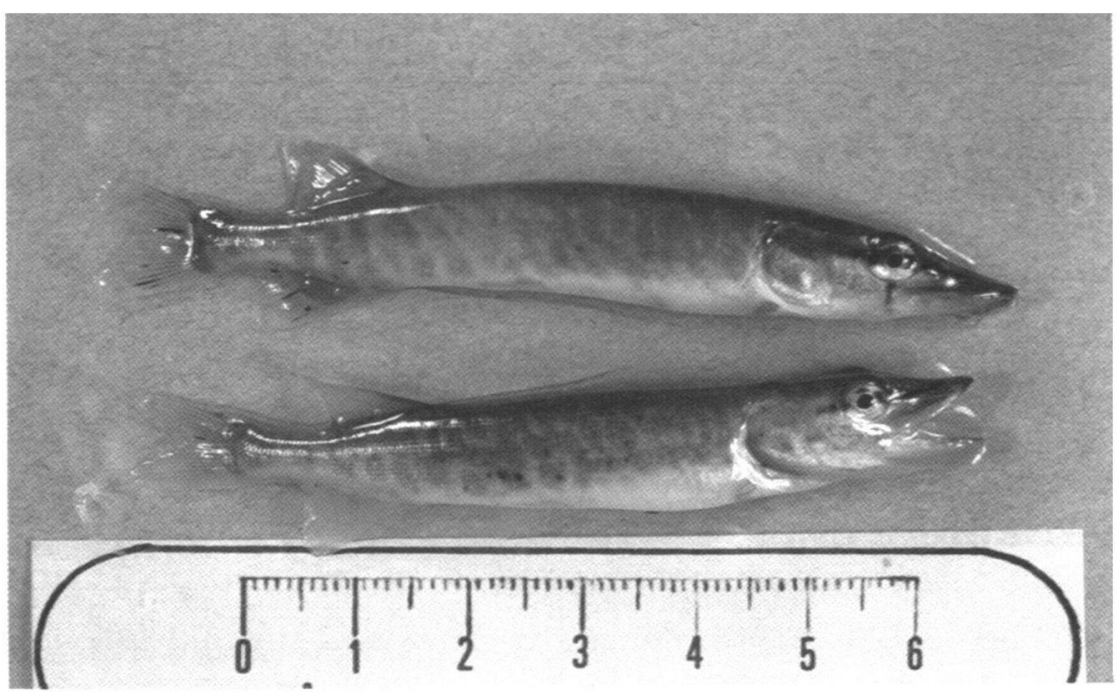

Figure 4 : Brochetons de 75 jours infectés par le virus de la SHV de type 3 à l'âge de 63 jours, avec des taches hémorragiques sur les flancs et les nageoires.

Figure 4 : Pike fingerlings (age : 75 days) infected by VHS type 3 when 63 days old, presenting haemorrhages on sides and fins.

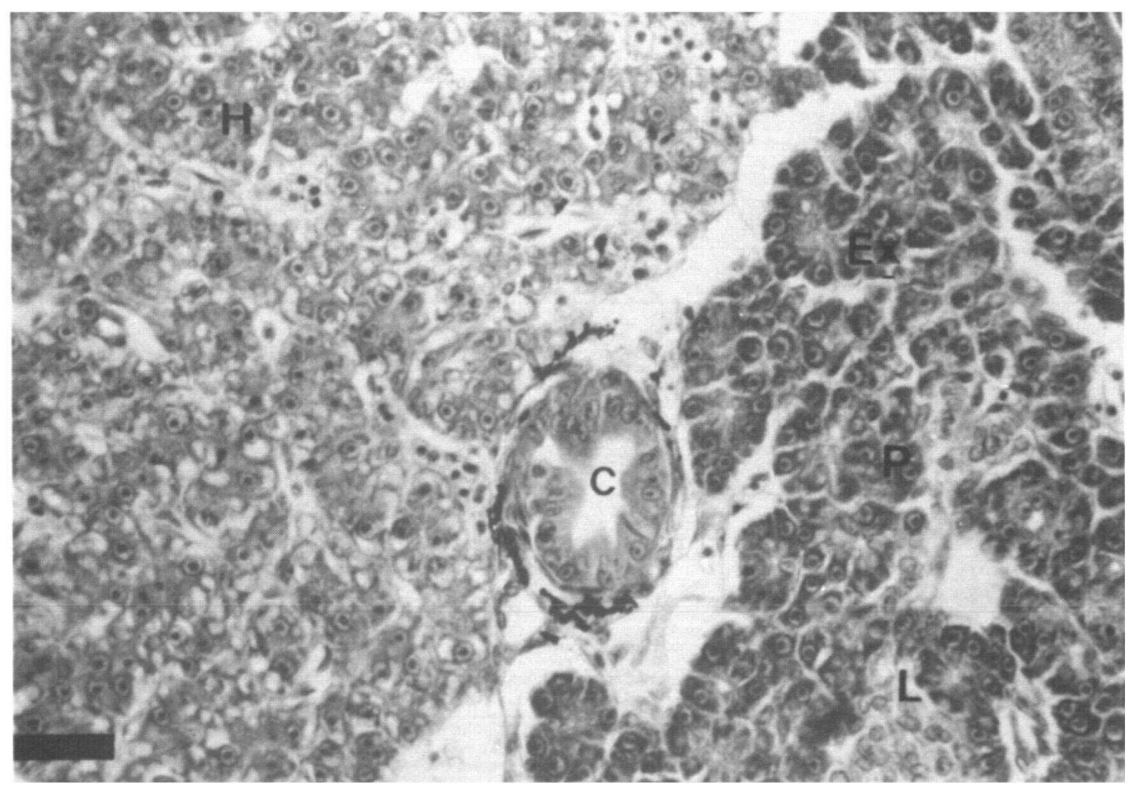

Figure 5 : Coupe d'alevin de brochet non infecté montrant l'aspect histologique normal des tissus hépatique $(H)$ et pancréatique $(P)$, ce dernier avec ses formations exocrine $(E x)$ et endocrine ( $L$, pour îlot de Langerhans), et une coupe transversale de canal cholédoque (C). Échelle : barre $=\mathbf{3 0} \mu \mathrm{m}$.

Figure 5 : Section of non infected pike fry showing the normal histological shape of hepatic $(H)$ and pancreatic (P) tissues. Pancreatic tissue involves exocrine structures (EX), endocrine structures ( $L$ for $L$ angerhans islets) and transversal section of choledoch (C). Bar $=30 \mu \mathrm{m}$. 


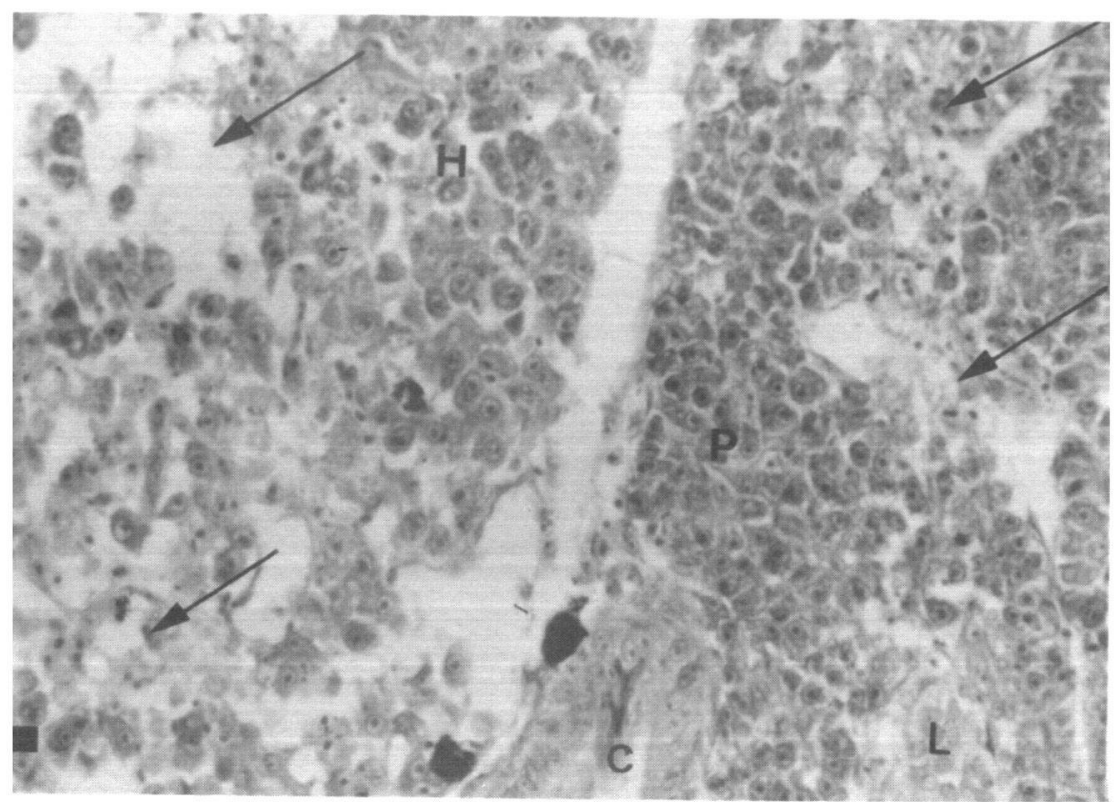

Figure 6 : Hépato-pancréatite nécrosante au cours de l'infection expérimentale de l'alevin de brochet par le virus de la nécrose pancréatique infectieuse (NPI). Les flèches indiquent les foyers de nécrose $H$ : foie, $P$ : pancréas. Un fragment de canal cholédoque est visible en coupe transversale (C) ainsi qu'un élément de tissu endocrine (L). Barre $=30 \mu \mathrm{m}$.

Figure 6 : Hepatic and pancreatic necrosis foci (arrows) in IPN infected free swimming pike fry. $H$ : liver, $P$ : pancreas. Choledoch $(C)$ is partly visible on the section which also involves a piece of endocrine tissue (L). Bar $=30 \mu \mathrm{m}$.

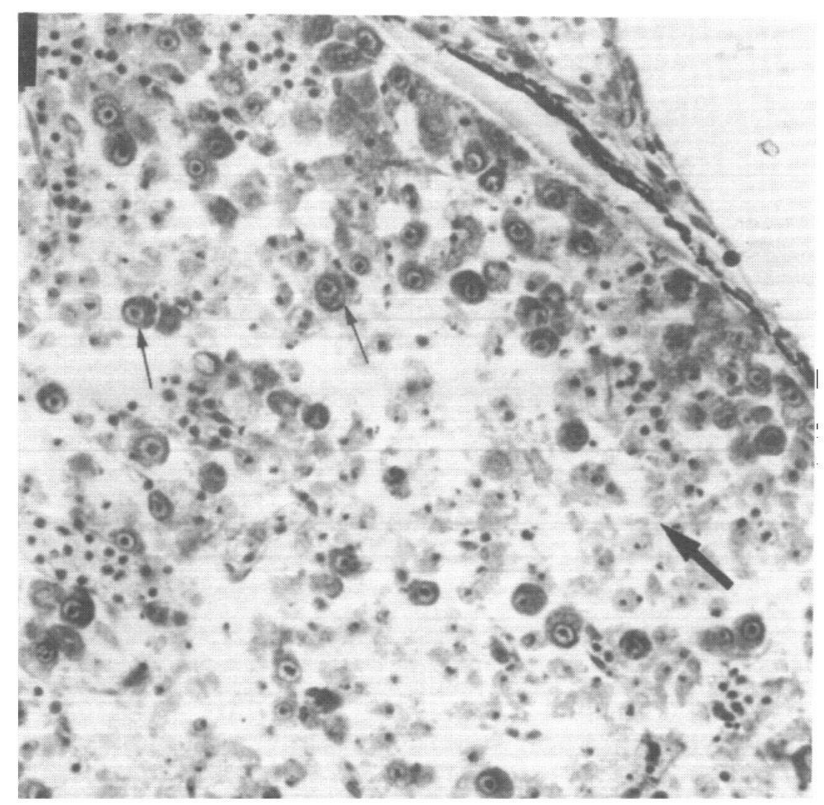

Figure 7 : Stade avancé de l'hépatite nécrosante induite par l'infection de l'alevin de brochet par le virus de la NPI. Seuls subsistent quelques hepatocytes normaux (flèche fine) dans le parenchyme hépatique dont la structure a disparu (flèche èpaisse).

Figure 7 : Advanced stage of IPN virus induced necrosing hepatitis. Scarce normal hepatocytes (thin arrow) remain among completely destroyed liver parenchyme (thick arrow). 


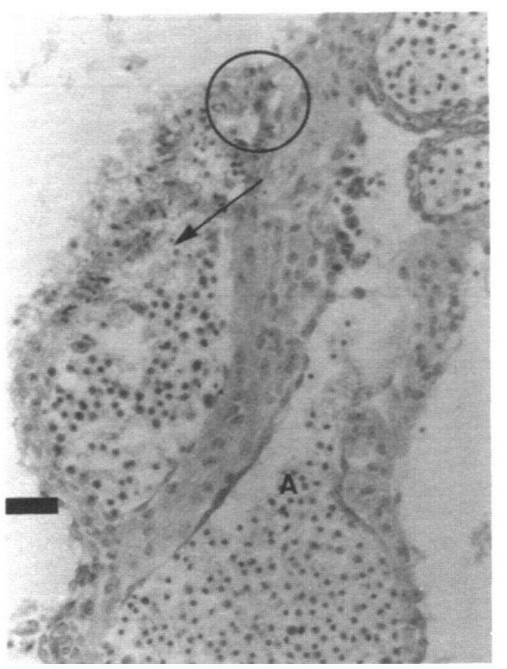

$8 \mathbf{a}$

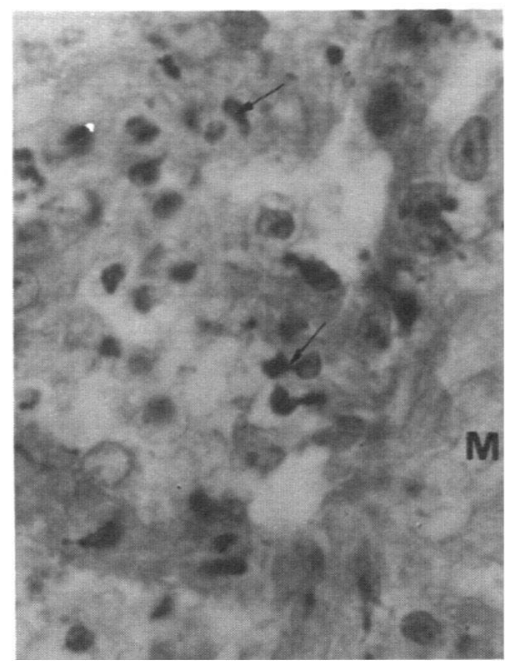

$\mathbf{8 b}$

Figure 8 : NPI expérimentale de l'alevin de brochet.

a. Lésion nécrotique de la paroi de l'atrium cardiaque $A$. On distingue une poche (flèche) contenant des cellules mononuclèes et des erythrocytes qui soulève une portion de myocarde et présente à la périphérie des éléments nécrotiques. Barre $=30 \mu \mathrm{m}$. Cercle : région agrandie en $\mathbf{8 b}$.

b. Vue de détail des éléments nécrosés (flèches fines) et d'une portion encore normale du myocarde $(\mathbf{M})$. Barre $=10 \mu \mathrm{m}$.

Figure 8 : Experimental IPN of pike fry.

a. Necrotic lesion of atrium wall of heart (A). A part of the wall is lifted up, delimiting a cavity (arrow) in which mononuclear cells and erythrocytes can be seen together with peripheric necrotic materials. Bar $=30 \mu \mathrm{m}$. Circle : area enlarged in $\mathbf{8 b}$.

b. Close up view of the wall lesion : necrotic materials (thin arrows) and normal cardiac muscular tissue (M). Bar $=10 \mu \mathrm{m}$.

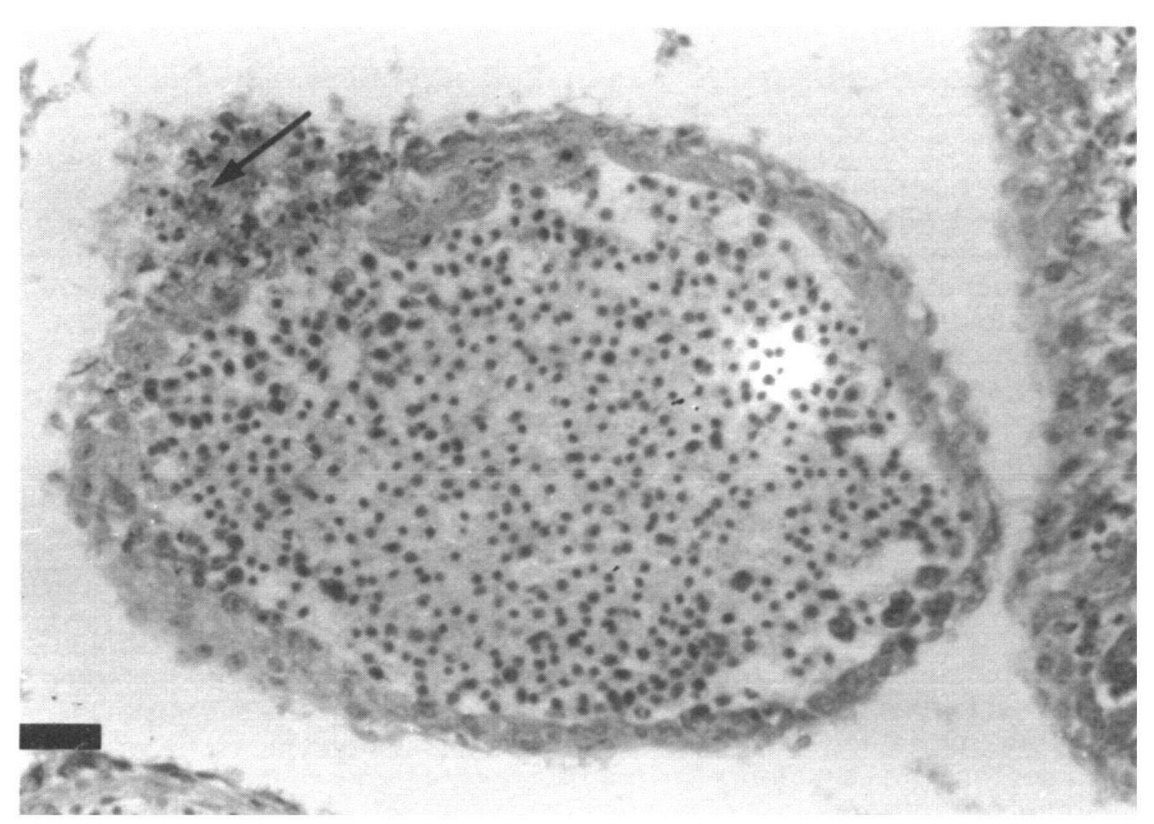

Figure 9 : NPI expérimentale de l'alevin de brochet: autre foyer de nécrose de la paroi atriale (flèche). Barre $=30 \mu \mathrm{m}$.

Figure 9 : Experimental IPN of pike fry: other necrotic focus of atrium wall (arrow). Bar $=30 \mu \mathrm{m}$. 

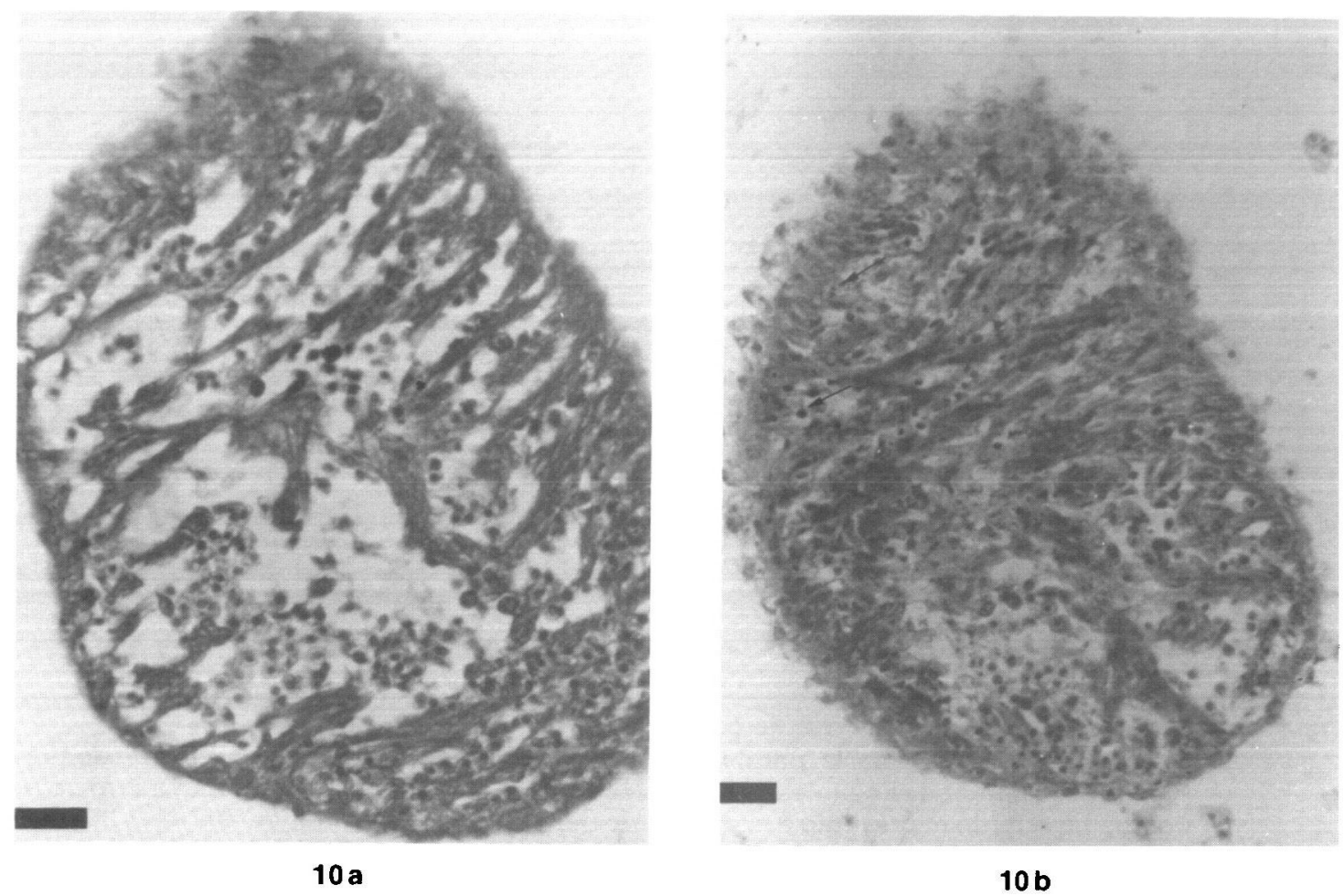

Figure 10 : Lésions ventriculaires dans la NPI expérimentale de l'alevin de brochet.

a. Ventricule normal, Barre $=30 \mu \mathrm{m}$.

b. Ventricule d'alevin infecté dans lequel on peut voir des noyaux pycnotiques dans l'endocarde (flèches). Barre $=30 \mu \mathrm{m}$.

Figure 10 : Ventricular lesions of experimentally IPN infected pike fry.

a. Section of ventricule of non infected fry. Barre $=30 \mu \mathrm{m}$.

b. Section of ventricule of infected fry in which pycnotic nuclei are present in endocardic tissue (thin arrows). Bar $=30 \mu \mathrm{m}$.

\section{DISCUSSION ET CONCLUSION}

La sensibilité du brochet au virus de la NPI, déjà annoncée par AHNE (1980) pour une souche virale isolée du brochet et semble-t-il non pathogène pour la truite, a été confirmée, avec cette fois-ci une souche virale tout-à-fait représentative des souches européennes pathogènes pour la truite arc-en-ciel. L'ontogénie de la résistance à ce virus apparaît encore plus rapide que dans le cas de la truite puisque des brochetons de deux mois se sont montrés résistants alors que les poissons âgés de 10 jours avaient subi une mortalité de $74 \%$, après une cinétique très comparable à celle qui est observée avec les salmonidés. Par contre, les signes cliniques et les lésions sont apparus différents: la nage désordonnée en vrille classique chez les salmonidés n'a jamais été observée chez le brochet, la mort étant précédée d'une simple prostration. Le ballonnement limité à la région gastrique chez les salmonidés a été ici remplacé par un gonflement généralisé lié à l'accumulation de liquide dans la cavité abdominale plus que dans l'estomac lui-même. L'exophtalmie, exceptionnelle chez les salmonidés atteints de NPI, a été fréquemment rencontrée chez les alevins de brochet, et peut-être ici attribuée elle aussi à une rétention liquidienne.

Les quatre rhabdovirus utilisés ont provoqué des mortalités significatives, avec des différences qui ne peuvent être considérées comme représentatives des pouvoirs pathogènes respectifs des virus considérés puisque les infections n'ont pas été simultanées. Cependant, on peut considérer que SHV type 3 est le plus pathogène (comme pour la truite arc-en-ciel) dans la mesure où il a provoqué la plus forte mortalité $(70 \%)$ chez les brochetons les plus âgés. Le virus de la NHI et le rhabdovirus de la perche sont sans doute les moins pathogènes. Le rhabdovirus de la perche mérite une mention particulière. puisque, à l'inverse des autres virus, la préparation infectante avait été obtenue après 60 passages en culture de cellules de truite. La raison en est que la production de ce virus avec des titres élevés avait nécessité une adaptation aux cellules de truite, d'une part, et que des perches n'avaient pas été disponibles pour entretenir la souche virale in vivo. On peut donc imaginer - hypothèse peu plausible - que le pouvoir pathogène pour le brochet ait été acquis au fil 
des passages en culture cellulaire. Néanmoins, la préparation virale utilisée ici n'était pas pathogène pour des alevins de truite âgés de six semaines. Dans tous les cas, les lésions obtenues avec les rhabdovirus s'apparentaient à celles qui sont observées avec les rhabdovirus pathogènes chez les salmonidés: hémorragies superficielles et internes, exophtalmie, les hémorragies apparaissant plus importantes avec les virus de la SHV. Le délai d'apparition des premiers morts a été compris entre 6 jours (SHV3) et 8 jours (NHI et RP).

L'étude histopathologique de la NPI, motivée par le caractère original des manifestations cliniques décrites plus haut, a confirmé des différences au niveau de la pathogénie. Les atteintes nécrotiques du pancréas, lésions considérées comme caractéristiques chez les salmonidés (SNIESZKO et al., 1957 ; Mc KNIGHT et ROBERTS, 1976) ont effectivement été retrouvées sur les brochets moribonds, mais accompagnées de sévères lésions hèpatiques qui n'ont été que très exceptionnellement observées chez la truite (DE KINKELIN et BESSE, 1966), ainsi que de lésions cardiaques, elles aussi inconnues chez la truite affectée de NPI. L'absence de lésions rénales a surpris, dans la mesure où l'observation clinique laissait supposer une perturbation du fonctionnement osmorégulateur du rein. L'absence de lésions musculaires (observées sur salmonidés par SNIESZKO et al., 1957 ; par DE KINKELIN et BESSE, 1966, mais pas par Mac KNIGHT et ROBERTS, 1976) et celle de lésions intestinales (soulignées par Mac KNIGHT et ROBERTS, 1976) accentuent la différence entre truite et brochet quant à la pathogénie de la NPI.

Les résultats exposés plus haut confirment, s'il en est besoin, la surprenante sensibilité du jeune brochet non seulement pour les principaux virus de salmonidés, mais encore pour un virus isolé au départ sur un poisson - la perche - phylogénétiquement éloigné du brochet et des salmonidés. Il est de toute façon heureux pour l'élevage du brochet qu'il se pratique en général de façon indépendante de celui des salmonidés.

\section{REMERCIEMENTS}

Ce travail a été réalisé dans le cadre d'une convention ( $n^{\circ} 2.576 \mathrm{~B}$ ) avec le Conseil Supérieur de la Pêche, et n'a été possible que grâce à la fourniture d'alevins par le Centre du Paraclet.

Les auteurs remercient Marie-Claire LE COCHENNEC pour la frappe du manuscrit.

\section{BIBLIOGRAPHIE}

AHNE W., 1978. Isolation and characterization of infectious pancreatic necrosis virus from $P$ ike (Esox lucius). Archives of Virology, 58, 65-69.

AHNE W., 1980. Occurence of infectious pancreatic necrosis virus (IPN) in different fish species. Berl. Munch. Tierarztl. Wochenschr. 93 (1), 14-16.

AMEND D.F., YASUTAKE W.T., MEAD R.W., 1969. A hematopoietic virus disease of rainbow trout and sockeye salmon. Trans. Am. Fish. Soc., 98. 796.

BRY C., SOUCHON Y., NEVEU G., TREBAOL L., 1983. Production de familles de brochetons en petits étangs par reproduction naturelle aménagée: bilan de trois années d'expérimentation et comparaison avec la méthode d'alevinage. In: R. BILLARD, (ed). Le Brochet: gestion dans le milieu naturel et élevage. INRA, Publ. Paris, 63-73.

DE KINKELIN P., BESSE P., 1966. Une epizootie de nécrose pancréatique dans les salmonicultures françaises. Bull Off. int. Epiz., 65 (7-8). 999-1010.

DE KINKELIN P., SCHERRER R., 1970. Le virus d'Egtved. I. Développement, stabilité, et structure de la souche danoise $F^{\prime}$. Annals of Veterinary Research I, 17-30.

DE KINKELIN P., GALIMARD B., BOOTSMA R., 1973. Isolation and identification of the causative agent of "Red disease" of Pike (Esox lucius L. 1766). Nature, 241 (5390), 465-467.

DE KINKELIN P., LE BERRE M., 1977. Isolement d'un rhabdovirus pathogène de la truite fario (Salmo trutta). C.R. Acad. Sc. Paris, 284, série D, 101-104.

DORSON M., DE KINKELIN P., MICHEL C., 1983. Pathologie du brochet. In: R. BILLARD (ed.). Le Brochet : gestion dans le milieu naturel et élévage. I.N.R.A., Publ. Paris, 1983, 245-250.

DORSON M., TORCHY C., CHILMONCZYK S., DE KINKELIN P., MICHEL C., 1984. A rhabdovirus pathogenic for perch, Perca fluviatilis L. : isolation and preliminary study. J. Fish Diseases, 7. 241-245.

JENSEN M.H., 1965. Research on the virus of Egtved disease. Ann. N.Y. Acad. Sci, 126, $422-426$.

MC KNIGHT I.J., ROBERTS R.J., 1976. The pathology of infectious pancreatic necrosis. I. The sequential histopathology of the naturally occuring condition. Br. vet. J., 32, 76. 
MEIER W., JORGENSEN P.E., 1980. Isolation of VHS Virus from Pike Fry (Esox lucius) with hemorrhagic symptoms. In: AHNE W. (Ed.). Fish Diseases, Illd COPRAQ Session, Springer-Verlag. Berlin-Heidelberg-New York, 8-17.

MULCAHY M.F., O'LEARY A., 1970. Cell free transmission of lymphosarcoma in the northern pike Esox lucius (Pisces: Esocidae). Experientia, 26, 891.

SNIESZKO S.F., WOOD E.M., YASUTAKE W.T., 1957. Infectious Pancreatic Necrosis in Trout. A.M.A. Arch. Pathol., 63, 229-233.

VESTERGARD-JORGENSEN P.E., KEHLET N.P., 1971. Infectious Pancreatic Necrosis (IPN) viruses in danish rainbow trout : their serological and pathogenic properties. Nord. Vet. Med., 23. 568-575.

WOLF K., QUIMBY M.C., 1962. Established eurythermic line of fish cells in vitro. Science, 135, 1065-1066. 